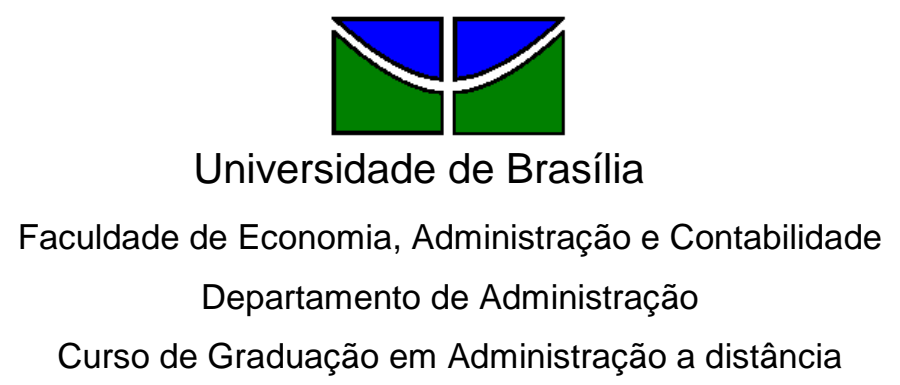

APARECIDA EVANGELISTA RODRIGUES NUNES

\title{
ACESSIBILIDADE DE CLIENTES COM DEFICIÊNCIA AUDITIVA AO BANCO DO BRASIL
}

Brasília - DF

2010 
APARECIDA EVANGELISTA RODRIGUES NUNES

\section{ACESSIBILIDADE DE CLIENTES COM DEFICIÊNCIA AUDITIVA AO BANCO DO BRASIL}

Professor Tutor: Mariana Marliere Létti, Mestra

Brasília - DF

2010 
Nunes, Aparecida Evangelista Rodrigues.

Acessibilidade de clientes com deficiência auditiva ao Banco do Brasil / Aparecida Evangelista Rodrigues Nunes. - Brasília-DF, 2010. $40 \mathrm{p}$.

Monografia (bacharelado) - Universidade de Brasília, Departamento de Administração - EaD, 2010.

Orientador: Profa Mariana Marliere Létti, Departamento de Administração.

Trabalho de Conclusão de Curso para obtenção do certificado no Curso de Administração

1. Deficiência auditiva. 2 Acessibilidade. 3. Responsabilidade Social. 4. Banco do Brasil 


\section{APARECIDA EVANGELISTA RODRIGUES NUNES}

\section{ACESSIBILIDADE DE CLIENTES COM DEFICIÊNCIA AUDITIVA AO BANCO DO BRASIL}

A Comissão Examinadora, abaixo identificada, aprova o Trabalho de Conclusão do Curso de Administração da Universidade de Brasília da aluna:

Aparecida Evangelista Rodrigues Nunes

Mariana Marliere Létti, Mestra

Professor-Orientador

Selma Lúcia de M. Gonzales, Doutora

Professor-Examinador
Maria Neuza, Mestra

Professor-Examinador

Brasília, 04 de dezembro de 2010. 


\section{DEDICATÓRIA}

Ao meu esposo Valter, aos meus filhos Danilo, Diego e Daniel pelo apoio, incentivo e compreensão. 
AGRADECIMENTOS

A Deus por ter me dado forças e garra para concluir este curso

A meus familiares que sempre acreditaram que eu conseguiria.

Ao Banco do Brasil que, através de parceria com a Universidade de Brasília, nos proporcionou esta oportunidade de crescimento pessoal e profissional. 


\section{POEMA DO SURDO}

O teu silencioso

É harmonioso

O teu jeito expressivo

É muito gostoso

Sabes sorrir

Sabes chorar

Sabes... É claro:

Te expressar!

O teu falar

Arrepia a gente

És falante de um sistema lingüístico

Muito diferente

Compreender a tua fala

O teu sentimento

É muito envolvimento

Esta língua, visual-especial

Quero aprender

Nos ensina... Teu modo de ver

Nos ensina... sentir e aprender

Nos ensina... saber, sobre as coisas do mundo.

\section{Autor Desconhecido}




\section{RESUMO}

A luta pelo reconhecimento e pela legitimidade dos direitos das pessoas com deficiência é antiga, mas somente a partir da promulgação da Constituição de 1988 houve a inserção efetiva do assunto na legislação federal, ainda que de forma tímida. Durante muitos anos a inclusão de pessoas com deficiência foi preocupação restrita dos profissionais da área de educação. Com o passar do tempo percebeu-se que para tornar a sociedade inclusiva, seria necessário adotar ações buscando oferecer tratamento e atendimento às pessoas com deficiências em qualquer setor da sociedade. Acessibilidade não significa apenas permitir que as pessoas com deficiência ou mobilidade reduzida participem de atividades que incluem o uso de produtos, serviços e informação, mas a inclusão e a extensão do uso destes por todas as parcelas de uma determinada população. Percebemos uma luta crescente da sociedade pela inclusão social para que as empresas atuem de forma socialmente responsável, para que as pessoas com deficiência usufruam de seus direitos e exerçam sua plena cidadania. Esta pesquisa qualitativa teve por objetivo verificar a eficácia das ações adotadas pelo Banco do Brasil em promoção de acessibilidade a clientes com deficiência auditiva no atendimento de suas agências localizadas no Distrito Federal, a partir de informações obtidas de funcionários de que ele estava oferecendo o curso de Linguagem Brasileira de Sinais (LIBRAS) a funcionários do atendimento ao público, atuantes no ambiente das agências e das respostas dadas por deficientes auditivos do banco. Entrevistamos funcionários que desenvolvem os projetos sociais e aplicamos um questionário a alguns deficientes auditivos de agências do DF. Pelas respostas dos entrevistados, percebemos que esses funcionários são apaixonados pelo que fazem e acreditam muito que o banco tem grande compromisso com a responsabilidade social, acreditam também que oferecendo um atendimento diferenciado aos deficientes auditivos, vai atrair novos nichos de mercado e captar novos negócios, mas não será muito significativo. Os clientes deficientes também acreditam que o banco está qualificando seus funcionários por compromisso com a responsabilidade social e para promover a inclusão dos surdos. Com base nos dados obtidos na pesquisa, e especialmente nos dados constantes na Carta de Princípios e Responsabilidade Social e na Agenda 21, que podem ser lidos no site do banco, acreditamos em suas ações sociais e que ele se aproximará mais do "atendimento de excelência", tão discutido nos dias atuais, conciliando às suas estratégias organizacionais.

Palavras-chaves: deficiência auditiva, acessibilidade, responsabilidade social, Banco do Brasil. 


\section{SUMÁRIO}

1 INTRODUÇÃO

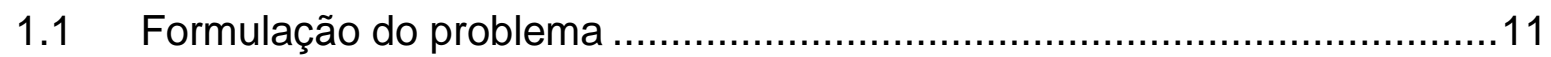

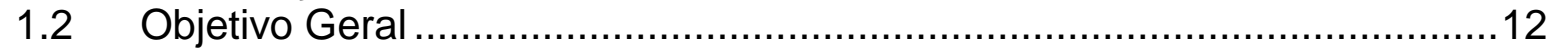

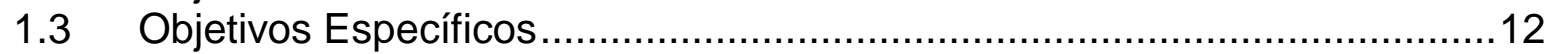

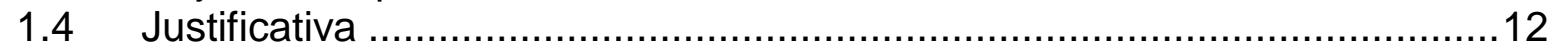

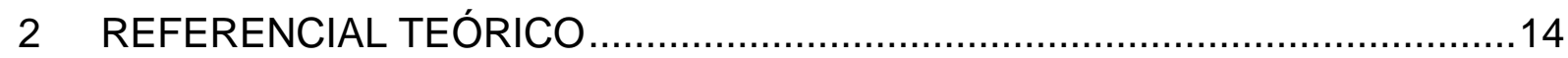

2.1 Contextualização histórica ..........................................................14

2.2 Legislação no Brasil ...............................................................16

2.3 Princípios ético e sócio ambientais no Banco do Brasil ............................18

2.4 Inclusão e responsabilidade social...................................................19

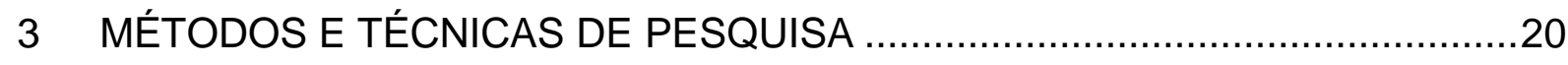

3.1 Caracterização da organização ……………...................................20

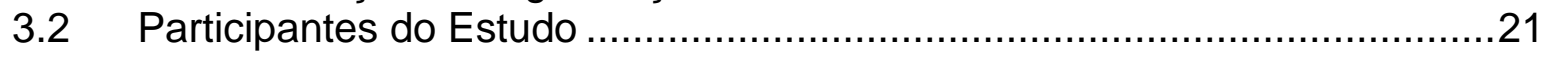

3.3 Caracterização dos instrumentos de pesquisa ........................................21

3.4 Descrição dos procedimentos de coleta e de análise de dados empregados 22

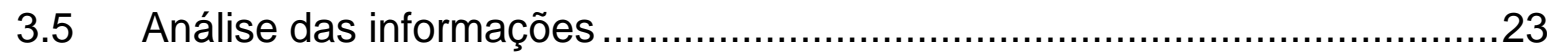

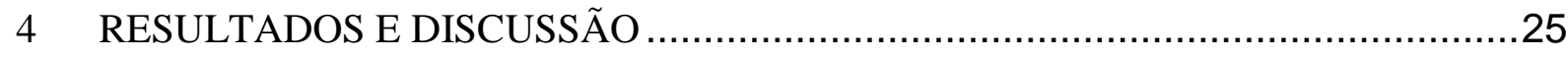

5 CONSIDERAÇÕES FINAIS E RECOMENDAÇÕES ........................................28

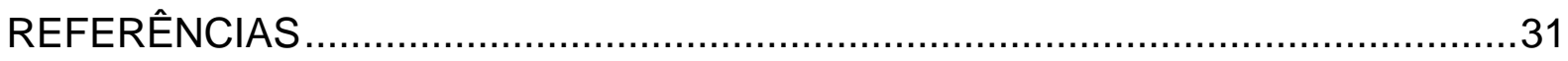

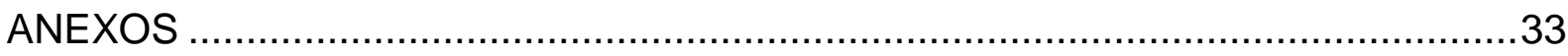

Anexo A - Primeira Entrevista Realizada ............................................................33

Anexo B - Questionário Aplicado aos Deficientes Auditivos.....................................37

Anexo C - Alfabeto Manual do Deficiente Auditivo ...................................................39 


\section{INTRODUÇÃO}

Durante muito tempo os deficientes foram considerados incapazes, sem condições de serem inseridos no mercado de trabalho, sem apoio ou iniciativas nem mesmo por parte do Governo para reduzir essa desigualdade, tornando-se alvo de preconceitos.

Somente no final da década de 1940 e início dos anos 50 o termo acessibilidade começou a ser usado com o conceito de reabilitação física e profissional, a expressão teve seu conceito ampliado, significando a eliminação de barreiras presentes no ambiente para que não houvesse mais segregação. Passou-se a perceber que o direito de todos à convivência é fundamental, que o que torna a humanidade maravilhosa é o convívio com a diversidade. Perceberam também que para promover a acessibilidade, era necessário fazer alterações na arquitetura urbana, nas edificações, nos sistemas e principalmente a necessidade de mudar atitudes, exigindo comprometimento de todos.

Em 1975 a Organização das Nações Unidas (ONU) - publicou a Declaração dos Direitos das Pessoas Portadoras de Deficiências. O ano de 1981 foi considerado Ano Internacional das Pessoas Deficientes.

No Brasil, a Constituição Federal de 1988 introduziu direitos às pessoas com deficiências. Desde então, várias leis têm sido publicadas, sempre ampliando os direitos e definindo critérios para a plena inclusão desse segmento social.

Somente após o Decreto 5.296 de dezembro de 2004, as empresas com mais de cem funcionários passaram a ter obrigatoriedade de reservar de 2 a 5\% do número de vagas a portadores de necessidades especiais.

O Decreto 5.296, de 2 de dezembro de 2004:

Regulamenta as Leis 10.048, de 8 de dezembro de 2000, dando prioridade de atendimento às pessoas que especifica, e 10.098, de 19 de dezembro de 2000 , estabelecendo normas gerais e critérios básicos para a promoção da acessibilidade, e se configura como um marco na história da legislação brasileira concernente às pessoas com deficiência. (D.O.U. de 03/12/2004, p. 5).

Somente a partir de sua vigência, o conceito de acessibilidade foi ampliado, deixando de ser meramente de caráter físico e arquitetônico, englobando elementos comunicacionais, programáticos, instrumentais, metodológicos e humanos.

Neste cenário, diversos setores têm mobilizado esforços pela diminuição dos problemas sociais e exclusivos, considerando que somente ações do governo são 
insuficientes; é necessário mobilização também da sociedade, do segundo e terceiro setor, representado por instituições com grande potencial para defender os interesses da sociedade civil (Organizações não Governamentais - ONG, Instituições Filantrópicas etc.).

O Banco do Brasil participa ativamente deste movimento, demonstrando um grande compromisso com a responsabilidade social, com a inclusão social e com a acessibilidade em suas unidades de atendimento ao público. Este banco se engajou no movimento de inclusão desde o início e para viabilizar ações eficazes nesse sentido, criou comitês de especialistas em elaboração de projetos.

Desde o início da implantação dos projetos de inclusão e acessibilidade houve questionamento se o banco estaria promovendo a inclusão por questão de responsabilidade social ou se buscava ter um diferencial competitivo e com isso conquistar novos clientes.

O objetivo deste estudo foi comprovar se o maior interesse seria mesmo a responsabilidade social, promovendo a inclusão de clientes com deficiência auditiva ou captação de novos nichos de mercado.

Este trabalho foi baseado principalmente em artigos publicados nos sites da Federação Brasileira dos Bancos (FEBRABAN), Banco do Brasil, Fundação Banco do Brasil e da Universidade Corporativa Banco do Brasil. Também foram realizadas entrevistas com as pessoas que estão desenvolvendo esses projetos, e que em 2008 conseguiram que o Banco oferecesse o curso de libras a seus funcionários a fim de qualificá-los para o atendimento aos clientes portadores de deficiência auditiva, pois acredita-se que um dos passos para comprovação aconteça fazendo entrevistas com os funcionários que se engajaram nesses projetos. 


\subsection{Formulação do problema}

A forma de gestão do Banco do Brasil exerce influência direta na transformação da sociedade. As decisões, ainda que internas, repercutem diretamente na vida dos colaboradores, suas famílias e na comunidade com a qual se relacionam. Promover a inclusão, respeitar a diversidade, faz parte do compromisso ético da empresa e contribui para a redução das desigualdades sociais. O Instituto Ethos (2002) afirma que esta realidade coloca a inclusão de pessoas com deficiência entre os temas mais importantes a serem tratados pelas empresas.

Segundo Sassaki (2002):

As empresas inclusivas caracterizam-se por demonstrarem transformações, pequenas e grandes, nos ambientes físicos (espaços internos e externos, equipamentos, aparelhos e utensílios, mobiliário e meio de transporte), nos procedimentos técnicos, nas formas de comunicação (visual, auditiva, por sinais, por computador) e na mentalidade de todas as pessoas, inclusive da própria pessoa com deficiência. (p. 45).

Há uma forte tendência no mundo organizacional de respeitar a diversidade, isso torna as empresas estrategicamente valorizadas. Se a empresa se portar com racismo ou discriminação, se torna alvo da mídia, repercutindo diretamente em sua credibilidade.

Nesse sentido, Bahia (2006) defende que:

A publicidade em torno de uma prática discriminatória pode ser bastante negativa para a organização, afetando sua imagem junto aos consumidores e à opinião pública. Por outro lado, na medida em que a diversidade seja um atributo característico das atividades da empresa, tornando-a conhecida como um bom lugar para trabalhar, com um ambiente aberto e inclusivo, ela pode agregar qualidades positivas à sua imagem no mercado. (p. 12).

Tendo por base o que defende Bahia (2006), é possível observar que promover a inclusão, respeitar a diversidade representa um valor estratégico de sucesso para as organizações, além de evidenciar a questão ética em seus negócios.

O Banco do Brasil está qualificando os funcionários do atendimento ao público nas agências para atender aos deficientes, especialmente os clientes com deficiência auditiva, oferecendo treinamento em Linguagem Brasileira de Sinais (LIBRAS), com isso, está promovendo a inclusão desse público em atendimento bancário.

Estaria o Banco do Brasil promovendo a inclusão por questão de responsabilidade social ou seria uma estratégia na busca de um diferencial competitivo para conquistar novos nichos de mercado? 


\subsection{Objetivo Geral}

O objetivo geral dessa pesquisa foi analisar a promoção da acessibilidade de clientes com deficiência auditiva ao Banco do Brasil, em agências localizadas no Distrito Federal.

\subsection{Objetivos Específicos}

Como objetivos específicos, pretendeu-se:

- Identificar, mediante levantamento bibliográfico específico, as políticas de promoção de inclusão de pessoas portadoras de deficiência auditiva vigentes no Brasil, contextualizando no âmbito das instituições financeiras;

- Analisar a legislação atinente à inclusão de pessoas com deficiência auditiva nas instituições financeiras;

- Analisar as políticas específicas adotadas pelo Banco do Brasil nas agências localizadas no Distrito Federal, sobre acessibilidade aos clientes portadores de deficiência auditiva;

- Verificar se as ações para acessibilidade e inclusão adotadas pelas agências localizadas no Distrito Federal satisfazem aos anseios e necessidades dos portadores de deficiência auditiva.

\subsection{Justificativa}

O tema Responsabilidade Social tem sido muito discutido no Brasil, as empresas estão se preocupando em fazer algo pelo social, reconhecendo que somente as ações do governo não são suficientes para resolução dos problemas sociais.

Compete à alta direção empresarial desenvolver conceitos corporativos na linha da responsabilidade social, não se preocupando apenas com a maximização de seus lucros, agregando novos valores empresariais e empreendedores, considerando a vida social e a conduta ética da empresa. Os consumidores hoje em dia são muito exigentes em relação aos 
preços e qualidades dos produtos de que necessitam, mas eles buscam também informações sobre ações sociais da empresa antes de comprar.

Adotar ações que promovam a acessibilidade e a inclusão de portadores de deficiências é mais importante do que se pensa. Ao ser questionado sobre ambientes que freqüenta, um surdo afirmou que ao escolher um ambiente, seja para lazer, estudos ou mesmo religiosos, busca aqueles locais freqüentados por outros surdos, ou que disponibilizam intérpretes da Língua Brasileira de Sinais - LIBRAS. Há que se considerar que isso também ocorra nas relações comerciais e financeiras. Trata-se de uma opinião individualizada, porém, contribui para a percepção da importância da acessibilidade à própria fidelização do usuário ou cliente.

A decisão de realizar essa pesquisa sobre acessibilidade a clientes com deficiências ao Banco do Brasil surgiu após contatos com alguns funcionários envolvidos diretamente nos projetos de responsabilidade social da empresa, principalmente no projeto de treinamento dos funcionários do atendimento aos clientes nas agências em um curso de LIBRAS, para que em toda agência haja pelo menos um funcionário habilitado para atendimento ao surdo.

Espera-se com essa pesquisa trazer subsídios que indiquem que o Banco, ao adotar ações de inclusão, não o faça apenas por cumprimento de lei, por preocupação com sua imagem perante seus clientes, nem tampouco visando somente atrair novos clientes ou maximização de seus lucros, mas que realmente esteja preocupado com a responsabilidade social e promovendo a inclusão das pessoas com deficiências, trazendo-lhes benefícios, afinal, eles também necessitam dos bancos. 


\section{REFERENCIAL TEÓRICO}

\subsection{Contextualização histórica}

Grande parte da população mundial passa por sérios problemas, tais como: a pobreza, a violência, a poluição, o analfabetismo, o preconceito, dentre outras. Todos acabam por refletir na sociedade, atingindo todas as camadas sociais.

Existem diversos programas sociais voltados para amenizar tantos problemas existentes, entretanto, não são suficientes, é necessário o engajamento de outros setores da sociedade para combater tantos problemas atuais.

Diante de tantas mudanças na evolução da sociedade, surge um novo movimento, o da inclusão, conseqüência de uma visão social, de um mundo democrático, onde se pretende respeitar direitos e deveres. A limitação da pessoa não diminui seus direitos: são cidadãos e fazem parte da sociedade como qualquer outro. É o momento de a sociedade se preparar para lidar com a diversidade humana. Todas as pessoas devem ser respeitadas, não importa o sexo, a idade, as origens étnicas, a orientação ou as deficiências.

Uma sociedade aberta a todos, que estimula a participação de cada um, aprecia as diferentes experiências humanas e reconhece o potencial de todo cidadão, é denominada sociedade inclusiva. A sociedade inclusiva tem como objetivo principal oferecer oportunidades iguais para que cada pessoa seja autônoma e autodeterminada. Dessa forma, a sociedade inclusiva é democrática, reconhece todos os seres humanos como livres e iguais e com direito a exercer sua cidadania.

Mas, para que uma sociedade se torne inclusiva, é preciso cooperar no esforço coletivo de sujeitos que dialogam em busca do respeito, da liberdade e da igualdade.

Como sabemos, nossa sociedade ainda não é inclusiva. Há grupos de pessoas discriminadas, inclusive nas denominações que recebem: inválido, excepcional, deficiente, mongol, down, manco, ceguinho, aleijado, demente etc. - o problema é do surdo, que não entende o que está sendo dito na TV, e não da emissora que não colocou a legenda; é do cego, por não saber das novas leis, e não do poder público que não as divulga oralmente ou em braile; é do deficiente físico que não pode subir escadas e não de quem aprovou uma 
construção sem rampas. Assim, dizemos que é de responsabilidade da pessoa com deficiência a sua integração à sociedade.

O termo inclusão, diferentemente, indica que a sociedade, e não a pessoa deve mudar. Para isso, até as palavras e expressões para denominar as diferenças devem ressaltar os aspectos positivos e, assim, promover mudança de atitudes em relação a essas diferenças. A promoção da inclusão pode acontecer a partir de ações e atitudes de qualquer cidadão.

Durante séculos, sociedades em todo o mundo foram indiferentes às pessoas com deficiência e estas acabaram sendo segregadas e excluídas do convívio social. Mas essa realidade tem sido modificada com o auxílio dos programas de inclusão social. A prática da inclusão social teve início há cerca de dez anos em várias partes do mundo. Consiste na adequação da sociedade para que ela possa incluir pessoas com deficiência em seus sistemas sociais e preparar estes indivíduos para que assumam seus papéis nas diversas comunidades. É um processo no qual os indivíduos excluídos e a sociedade buscam, em parceria, equacionar problemas, encontrar soluções e efetivar a equiparação de oportunidades para todos.

De acordo com a FEBRABA (2006) "Cabe à sociedade eliminar todas as barreiras físicas, programáticas e 'atitudinais' para que as pessoas com deficiência tenham acesso a serviços, espaços, informações e bens necessários a seu desenvolvimento pessoal, social, educacional e profissional"

\footnotetext{
Números recentes evidenciam a importância do segmento para a economia brasileira. Existem no País 24,6 milhões de pessoas com algum tipo de deficiência, o que equivale a $14,5 \%$ da população, segundo o Censo 2000 realizado pelo IBGE. Desse total, $48 \%$ apresentam deficiência visual, $23 \%$ deficiência motora, 16\% deficiência auditiva, $9 \%$ deficiência mental e $4 \%$ deficiência física. Se multiplicarmos esse total por três - supondo que cada pessoa com deficiência mora, no mínimo, com duas pessoas (pai e mãe) -, teremos 81 milhões de pessoas que lidam diariamente com essa realidade. Isso equivale a $45 \%$ da população, ou quase um em cada dois brasileiros. E o bom funcionamento da economia brasileira deve muito a esse considerável contingente de cidadãos. (FEBRABAN, 2006, p. 12).
}

Os dados do Censo são referentes a qualquer tipo de deficiência, não somente às pessoas consideradas incapazes, são incluídas nessa pesquisa pessoas com dificuldades de enxergar, ouvir ou caminhar, são milhões de cidadãos que compõem uma parcela nada desprezível de nossa população.

A deficiência visual - não necessariamente cegueira total - é a mais presente nos brasileiros, representando quase a metade $(48,1 \%)$ da população com deficiência. Logo em seguida vêm as deficiências motoras e físicas que, em conjunto, somam $27,1 \%$. A terceira maior incidência é a deficiência auditiva $(16,6 \%)$ - considerados os diferentes graus de perda auditiva, desde a surdez leve até anacusia - e por 
último, aparece a deficiência mental, que atinge 8,2\% do total de indivíduos com deficiência. (FEBRABAN, 2006, p. 12).

\subsection{Legislação no Brasil}

A partir de recomendações e resoluções internacionais, diversos países estão reformulando suas legislações visando o respeito aos direitos de cidadãos portadores de necessidades especiais:

A Lei $\mathrm{n}^{\circ} 7.853 / 89 \mathrm{em}$ seu art. $2^{\circ}$ estabelece:

Ao poder público e seus órgãos cabe assegurar às pessoas portadoras de deficiência o pleno exercício de seus direitos básicos, inclusive dos direitos à educação, à saúde, ao trabalho, ao lazer, à previdência social, ao amparo à infância e à maternidade, e de outros que, decorrentes da Constituição e das leis, propiciem seu bem-estar pessoal, social e econômico. (Brasil, 1989, p. 2).

O Decreto Lei 3298/99 em seu Art. $36^{\circ}$ estabelece:

A empresa com cem ou mais empregados está obrigada a preencher de dois a cinco por cento de seus cargos com beneficiários da Previdência Social reabilitados ou com pessoa portadora de deficiência habilitada, na seguinte proporção:

I - até duzentos empregados, dois por cento;

II - de duzentos e um a quinhentos empregados, três por cento;

III - de quinhentos e um a mil empregados, quatro por cento; ou

IV - mais de mil empregados, cinco por cento. (Brasil, 1999, p. 50).

Este decreto facilitou a vida do deficiente, que não depende mais somente de si para ser reintegrado à sociedade, espera-se que os Órgãos Públicos, empresas privadas e outras instituições adaptem seu ambiente físico e social para receber essas pessoas, que amparadas por legislação, terão vagas garantidas.

Em 2008, houve a Convenção da ONU sobre os direitos das pessoas com deficiência, com o propósito de promover, proteger e assegurar o desfrute pleno e eqüitativo de todos os direitos humanos e liberdades fundamentais por parte de todas as pessoas com deficiência e promover o respeito pela sua inerente dignidade. Entre seus propósitos podem ser destacados:

- "Comunicação" abrange as línguas, a visualização de textos, o braile, a comunicação tátil, os caracteres ampliados, os dispositivos de multimídia acessível, assim como a linguagem simples, escrita e oral, os sistemas auditivos e os meios de voz digitalizada e os modos, meios e formatos aumentativos e alternativos de comunicação, inclusive a tecnologia da informação;

- "Língua" abrange as línguas faladas e de sinais e outras formas de comunicação não-falada; 
- "Discriminação por motivo de deficiência" significa qualquer diferenciação, exclusão ou restrição baseada em deficiência, com o propósito ou efeito de impedir ou impossibilitar o reconhecimento, o desfrute ou o exercício, em igualdade de oportunidades com as demais pessoas, de todos os direitos humanos e liberdades fundamentais nas esferas política, econômica, social, cultural, civil ou qualquer outra. Abrange todas as formas de discriminação, inclusive a recusa de adaptação razoável;

- “Ajustamento razoável" significa a modificação necessária e adequada e os ajustes que não acarretem um ônus desproporcional ou indevido, quando necessários em cada caso, a fim de assegurar que as pessoas com deficiência possam desfrutar ou exercitar, em igualdade de oportunidades com as demais pessoas, todos os direitos humanos e liberdades fundamentais;

- "Desenho universal" significa o projeto de produtos, ambientes, programas e serviços a serem usados, na maior medida possível, por todas as pessoas, sem que seja necessário um projeto especializado ou ajustamento. O "desenho universal" não deverá excluir as ajudas técnicas para grupos específicos de pessoas com deficiência, quando necessárias. (FEBRABAN 2006, p. 14).

Segundo Edmarcius (2010, p. 36) o termo portador, embora conste no texto constitucional e em outras leis posteriores, é incorreto. Àquela época, o legislador visava tão somente não utilizar de palavras com conotação negativa, como surdo-mudo, retardado e outros. Segundo ele, Portador de necessidades especiais dá o sentido que a pessoa está portando sua deficiência, assim como porta consigo, por exemplo, objetos pessoais, os quais podem deixar de carregar quando bem desejar. Qualquer ser humano está sujeito a necessidades especiais, que podem ser de ordem econômica, social, sentimental ou mesmo por ser idosa, obesa, grávida etc. Segundo o autor, o termo correto é pessoa com deficiência, porque retrata sem ofensas tal realidade. Segundo ele, embora o termo portador conste no texto Constitucional, não necessita de uma emenda para correção, porém, vale a análise contextual de seu surgimento e o atual entendimento, para que os próximos textos legislativos sejam diferentes.

Segundo a douta Fávero (2004, p. 27) “A pessoa com deficiência não é incapaz, em uma perspectiva amplificada, pois caso assim fosse, representaria, no mínimo, um retrocesso a todo esforço de décadas para que a deficiência não seja vista de forma dissociada da ausência de potencialidades".

A Lei $\mathrm{n}^{\circ} 10.098$, de 19 de dezembro de 2000 estabelece:

Normas gerais e critérios básicos para a promoção da acessibilidade das pessoas portadoras de deficiência ou com mobilidade reduzida. No Capítulo VII, art. 17 e 18 estabelece a promoção, por meio do Poder Público, da eliminação das barreiras da comunicação para garantir às pessoas "portadoras de deficiências sensoriais e com dificuldades de comunicação o acesso à informação, à educação..." e ainda, "a formação de profissionais intérpretes de língua de sinais para facilitar qualquer tipo 
de comunicação direta à pessoa portadora de deficiência sensorial e com dificuldade de comunicação". (FEBRABAN, 2006, p. 6).

Foi através da Lei $\mathrm{n}^{\circ} 10.436$, de 24 de abril de 2002, que as garantias individuais do surdo e o pleno exercício da cidadania alcançaram respaldo institucional decisivo, e foi reconhecido o estatuto da Linguagem Brasileira de Sinais como língua oficial da comunidade surda, com implicações para sua divulgação e ensino, para o acesso bilíngüe à informação em ambientes institucionais e para a capacitação dos profissionais que trabalham com surdos.

\subsection{Princípios ético e sócio ambientais no Banco do Brasil}

O Banco do Brasil é um dos principais agentes de desenvolvimento econômico e social do País, a expressão dessa postura está na Carta de Princípios de Responsabilidade Socioambiental e na Agenda 21, que pode ser lida no site do Banco:

\footnotetext{
A postura de responsabilidade socioambiental do Banco do Brasil tem como premissa a crença na viabilidade de se conciliar o atendimento aos interesses dos seus acionistas com o desenvolvimento de negócios social e ecologicamente sustentáveis, mediante o estabelecimento de relações eticamente responsáveis com seus diversos públicos de interesse, interna e externamente. Vai além, acredita que esta postura contribua para o desenvolvimento de um novo sistema de valores para a sociedade que tenha como referencial maior o respeito à vida humana e ao meio ambiente, condição indispensável à sustentabilidade da própria humanidade.
}

Citamos abaixo alguns dos compromissos do banco contidos na Carta de Princípios e na Agenda 21:

- Reconhecer que todos os seres são interligados e toda forma de vida é importante;

- Repelir preconceitos e discriminações de gênero, orientação sexual, etnia, raça, credo ou de qualquer outra espécie;

- Enxergar clientes e potenciais clientes antes de tudo como cidadãos;

- Contribuir para a universalização dos direitos sociais e da cidadania;

- Contribuir para a inclusão de pessoas com deficiência. 


\subsection{Inclusão e responsabilidade social}

Empresas que se preocupam com a responsabilidade social se comprometem com ações que atendam às demandas de conscientização da sociedade, pondera os impactos sociais e ambientais decorrentes da atuação administrativa e negocial.

O paradigma da inclusão surgiu na década de 1990 e despertou na sociedade a necessidade de modificações estruturais e conjunturais em seus sistemas gerais ou comuns, a fim de que qualquer pessoa, tenha ela deficiência ou não, exerçam seus direitos e deveres dentro da comunidade, sem barreiras atitudinais, arquitetônicas, comunicacionais ou metodológicas.

A qualidade da relação que a empresa mantém com seu público interno e externo diante da disponibilidade cada vez maior de recursos tecnológicos, está diretamente relacionada à questão da inclusão ou exclusão de diferentes grupos sociais, com múltiplas culturas, visões de mundo e estilos de trabalho, se tornando uma vantagem competitiva.

Segundo Bahia (2006, p. 45), "as práticas inclusivas adotadas pelas empresas são justificadas e reforçadas por uma série de benefícios por elas trazidos. Entretanto, este retorno depende do quanto de empenho é investido na implantação da política de inclusão social".

A promoção da acessibilidade faz parte do compromisso ético de promover a diversidade, respeitar as diferenças e reduzir as desigualdades sociais. O Instituto Ethos (2002, p. 44) afirma que esta realidade coloca a inclusão de pessoas com deficiência entre os temas mais importantes a serem tratados pelas empresas.

Ao oferecer qualificação em Linguagem Brasileira de Sinais (LIBRAS) a funcionários do atendimento ao público nas agências do Distrito Federal para atender aos deficientes auditivos, o Banco do Brasil está demonstrando sua preocupação em promover a acessibilidade e inclusão desse público em seu atendimento bancário.

Estaria o banco promovendo a inclusão e acessibilidade por questão de responsabilidade social ou seria uma estratégia na busca de um diferencial competitivo para conquistar novos nichos de mercado? 


\section{MÉTOdOS E TÉCNICAS DE PESQUISA}

Metodologia, segundo Matias (2006), deve necessariamente:

- Fornecer o detalhamento da pesquisa. Caso o leitor queira reproduzir a pesquisa, ele terá como seguir os passos adotados;

- Esclarecer os caminhos que foram percorridos para chegar aos objetivos propostos;

- Apresentar todas as especificações técnicas materiais e dos equipamentos empregados;

- Indicar como foi selecionada a amostra e qual seu percentual em relação à população estudada;

- Apontar os instrumentos de pesquisa utilizados (observação, questionário, entrevista etc.);

- Mostrar como os dados foram tratados e como foram analisados;

- Resultados (análise e discussão). (p. 83).

Com base em definições sobre tipos de pesquisa e em suas relações com o tema escolhido, a pesquisa foi do tipo exploratório-qualitativa. Exploratório por explorar um tema que ainda pode ser discutido com mais profundidade, qualitativa porque não utiliza técnicas estatísticas. O número de clientes bancários com deficiência auditiva, tomando por base pesquisa realizada e publicada no site da FEBRABAN ainda é pequeno, insuficiente para tratamento de amostragem estatística. Para a realização desta pesquisa do tipo qualitativa, baseamos em dados obtidos de funcionários lotados nos setores responsáveis pela elaboração de projetos de Responsabilidade Social do Banco do Brasil sobre as ações, já adotadas ou em estudo, para promoção de acessibilidade e inclusão de deficientes auditivos ao banco. Posteriormente, para verificar a eficácia desses projetos, aplicamos um questionário a dez clientes do banco com deficiência auditiva.

Segundo Acevedo (2009, p. 46) “o principal objetivo da pesquisa exploratória é proporcionar maior compreensão do fenômeno que está sendo investigado, permitindo assim que o investigador delineie de forma mais precisa o problema”.

\subsection{Caracterização da organização}

A organização escolhida foi o Banco do Brasil, considerando agências localizadas no Distrito Federal, e suas ações no sentido de promover a acessibilidade a portadores de 
necessidades especiais e principalmente a ação de disponibilizar treinamento no curso de Linguagem Brasileira de Sinais - LIBRAS a seus funcionários para estarem aptos a prestar um atendimento de excelência a clientes deficientes auditivos.

\subsection{Participantes do Estudo}

A população participante do estudo foram os portadores de necessidades especiais, mais especificamente os deficientes auditivos clientes de agências do Banco do Brasil localizadas no Distrito Federal, e sua inclusão na instituição.

As entrevistas foram realizadas com os funcionários da instituição Banco do Brasil, diretamente envolvidos nos projetos de inclusão adotados pelo banco, principalmente aqueles voltados para a inclusão de clientes com deficiência auditiva no atendimento das agências, qualificando seus funcionários. Posteriormente foram entrevistados alguns clientes da instituição que possuem deficiência auditiva.

\subsection{Caracterização dos instrumentos de pesquisa}

As entrevistas foram realizadas de forma semi-estruturada, baseando apenas em algumas questões guias, aplicada face a face pela entrevistadora, utilizando gravador de voz, para garantir o teor das respostas.

Foram entrevistadas seis pessoas, funcionários da instituição financeira escolhida, lotados na Diretoria de Gestão de Pessoas (DIGES) e de Desenvolvimento Regional Sustentável (DRS) do Banco do Brasil, em Brasília, Distrito Federal, e que de alguma forma estão envolvidos em projetos sociais e de inclusão promovidos pela empresa, especialmente na introdução do curso de libras aos funcionários, com a finalidade de oferecer um atendimento especializado aos clientes do banco, seja pela inclusão social e promoção de acessibilidade, captação de negócios, explorando novos nichos de mercado, ou ambos. Foi também aplicado um questionário a dez deficientes auditivos, todos clientes da instituição financeira objeto dessa pesquisa, a fim de identificar o impacto das ações adotadas pelo banco na vida desses deficientes. 


\subsection{Descrição dos procedimentos de coleta e de análise de dados empregados}

Através das entrevistas, obtivemos os dados primários sobre os projetos do banco. Os dados secundários, através de levantamento bibliográfico em livros, jornais, revistas e principalmente obtidos no site do Banco do Brasil, no Sistema de Informações Banco do Brasil (SISBB), no site da Fundação Banco do Brasil, da Universidade Corporativa Banco do Brasil e da Federação Brasileira dos Bancos (FEBRABAN), além da utilização de dados levantados pelo IBGE (Censo, 2000).

As entrevistas foram realizadas com seis funcionários do Banco do Brasil, participantes dos projetos de inclusão aos clientes deficientes auditivos no atendimento das agências; foi aplicado também um questionário a dez deficientes auditivos clientes do banco, para comprovar ou não a eficácia desses projetos.

Após a realização das entrevistas e a transcrição das informações, foi feita uma análise a partir da técnica de análise de conteúdo, de acordo com Franco (2003), buscando-se identificar categorias condizentes ao objeto do estudo, seguindo as seguintes categorias: grau de comprometimento; inclusão social, qualidade de vida, excelência no atendimento e captação de negócios.

Através da análise das entrevistas aos funcionários, foi possível verificar sua percepção em relação ao treinamento em LIBRAS oferecido pelo banco; através da análise do questionário aplicado aos deficientes clientes do banco, foi possível verificar a eficácia desse projeto e seu impacto na vida desses deficientes.

Antes da aplicação das entrevistas, foi efetuado um pré-teste com um dos funcionários selecionados e foi possível observar a possibilidade de satisfazer ao objetivo da pesquisa sem alterações nas perguntas anteriormente elaboradas. Foi feito também entrevista com um surdo cliente do banco e foi possível observar que como as perguntas eram subjetivas, haveria dificuldade de interpretação e descrição das opiniões, o que comprometeria o alcance dos objetivos da pesquisa, desta forma, foram feitas alterações no questionário, que passou a ser apenas objetivo. 


\subsection{Análise das informações}

Através das entrevistas realizadas, foi possível conhecer a percepção dos funcionários entrevistados com relação ao Curso de Libras, foi possível observar que os entrevistados acreditam que oferecendo o curso de libras a seus funcionários, o banco demonstra sua responsabilidade social não apenas por uma questão legal, mesmo antes da lei que obriga toda empresa de atendimento ao público ter pessoas treinadas para atendimento ao deficiente auditivo já havia essa preocupação por parte do banco em treinar seus funcionários.

Quanto a inclusão social, há também a crença por parte dos funcionários do Banco do Brasil de que o fato de oferecer treinamento fará com que os surdos se sintam inseridos no banco, mas acrescentam que somente falar a Libras não será suficiente para que o surdo perceba essa inclusão, é preciso treinamento e conscientização dos funcionários na mudança de atitudes para com o deficiente, segundo um dos funcionários entrevistados: "não adianta implantar rampas, ensinar libras..., se não mudar a atitude das pessoas, ele acredita ainda que haverá captação de negócios e novos clientes, mas que isso não é o objetivo, será apenas uma conseqüência.

Todos os entrevistados acreditam que, para o surdo, ser atendido por alguém que foi treinada na linguagem dele para que prestasse um atendimento diferenciado, isso vai sim trazer satisfação, ele vai se sentir valorizado e isso contribuirá para sua qualidade de vida, sempre que precisar de atendimento bancário, vai procurar aquela agência que tem esse diferencial, o melhor para o banco é que ele vai levar a comunidade dele, como conseqüência, trará lucratividade para a empresa.

Os funcionários entrevistados se envolveram de tal forma em projetos de inclusão de deficientes, especialmente a deficiência auditiva (objeto dessa pesquisa) que acreditam que com os projetos de inclusão, o banco se aproximará mais do tão sonhado "atendimento de excelência", tão falado em qualquer instituição hoje em dia.

Quando à captação de negócios, consideram que o público com deficiências usuários dos serviços bancários ainda é pequeno, mas que deve ser considerado que eles tem família, amigos, então eles trarão novos clientes, especialmente por ter recebido um atendimento diferenciado, alguém virá com eles, a comunidade surda é muito unida, "fez para um surdo, fez para todos, eles " (frase de um funcionário entrevistado). Eles trarão a comunidade deles e conseqüentemente haverá captação de negócios, acreditam que em qualquer ação do banco, 
instituição capitalista, há intenção de captação de negócios, mas nesse caso, há também um compromisso com o social.

A aplicação do questionário com o deficiente surdo foi bastante complicada, houve dificuldades de encontrar surdos que tem fluência com a língua portuguesa e com a Libras, além do mais, para atender aos objetivos da pesquisa, o questionário foi aplicado somente a pessoas inseridas no mercado de trabalho e bancarizados, capacitados a uma mínima interação. Para facilitar o entendimento sobre o que se pretendia com a aplicação do questionário, fornecemos a cartilha sobre acessibilidade elaborada pela Fundação Banco do Brasil para expor sobre o projeto de acessibilidade do banco, percebeu-se que após ler a cartilha, ficou mais fácil para eles entenderem o objetivo do questionário e que havia realmente essa preocupação por parte do banco. Houve efetividade nas respostas e satisfação dos objetivos da pesquisa.

Pelas respostas obtidas, foi possível perceber que esses deficientes ainda sentem dificuldades no atendimento bancário, a maioria deles ainda não percebeu essa inclusão. Comprovou-se também que a maioria, quando necessita de atendimento na agência, vem sozinho e todos responderam que utilizam o Terminal de Auto Atendimento - TAA sem necessidade de acompanhante, apenas um disse que embora consiga utilizar o auto atendimento sozinho, por questão de segurança normalmente quando vai realizar saque, prefere ir acompanhado. A maioria não conhece o sistema de Terminal Telefônico para Surdos - TDD/TTS, recurso implantado desde 2006 pelo Banco do Brasil especialmente para atendimento a esses indivíduos. 


\section{RESULTADOS E DISCUSSÃO}

Com esta pesquisa, percebemos a importância de se desenvolver temas relacionados à comunidade surda, em dados estatísticos divulgados no site da FEBRABAN (2006), é expressiva a quantidade de indivíduos nesta condição no Brasil e no mundo, sendo grande parte economicamente ativa e usuária de produtos e serviços bancários.

A existência de diversos decretos e leis relacionados a deficiências demonstra a importância que se deve dar ao estreitamento dessa relação, em que as instituições financeiras devem se adequar às normas de acessibilidade física ao ambiente, produtos e serviços bancários, e principalmente deve qualificar e conscientizar seus funcionários para o atendimento desses clientes nas agências e que em cada uma deve ter pelo menos um funcionário treinado em Língua Brasileira de Sinais - LIBRAS para atender ao deficiente auditivo, seja por compromisso com a responsabilidade social ou mesmo por força de lei vigente.

Através das entrevistas aplicadas aos funcionários que participam diretamente do processo de inclusão no Banco do Brasil, foi possível constatar com as informações colhidas que eles reconhecem o alto grau de comprometimento da organização no que tange a responsabilidade social.

Igualmente reconhecem a importância do Curso de Libras no processo de inclusão social, bem como a possibilidade do mesmo proporcionar qualidade de vida ao funcionário e a pessoa do funcionário e trazer ganhos na imagem da instituição, gerando novos negócios, por mais que esta não seja a proposta fim.

Entre os funcionários entrevistados, três participam na parte administrativa e são extremamente envolvidos e empolgados com o trabalho que desenvolvem, acreditam que o curso de Libras, bem como outras ações propostas vão mudar a vida dos clientes surdos e dos funcionários qualificados.

Diante dos resultados colhidos com as entrevistas, é possível verificar que a responsabilidade social requer a participação e o comprometimento de todos os envolvidos para que haja efetividade e eficácia nas ações promovidas.

Qualquer iniciativa empresarial e governamental que envolve mudanças de conceitos requerem planejamento, acompanhamento e correções, se necessárias. Na implantação, deve ainda envolver todos que são afetados direta e indiretamente. 
No caso em questão, além do envolvimento das pessoas, haverá necessidade de muita dedicação, pois ao adotar ações de inclusão do surdo, a instituição lidará com pessoas que durante muitos anos foram totalmente excluídos e reprimidos, vai envolver sentimentos, há de se ter muito tato, delicadeza e empatia para que os medos arraigados possam aos poucos serem quebrados e possam gerar os resultados de inclusão propostos.

Através das entrevistas com os funcionários envolvidos nos projetos de ações sociais do banco, diversas frases foram ditas que aumentam a credibilidade dessas ações, citamos abaixo algumas delas:

"Eu sinto que o banco se sente responsável em treinar as pessoas de modo que elas possam se comunicar com os surdos e trazer essas pessoas para dentro do banco como clientes e recebê-las da melhor forma possível, isso não envolve somente uma questão legal, mas já era proposta da empresa desenvolver um treinamento específico para disponibilizar aos funcionários a questão da língua de sinais".

"Além dos novos nichos a gente tá verificando a necessidade de ter uma política que todos possam ser atendidos de uma forma bem universal, assim como os colegas tem essa necessidade, pessoas surdas estão entrando agora, há a questão também do idoso que com o tempo tem problemas visuais, problemas de audição, então são todas políticas que a gente tá atendo, e o banco tem feito esforços para desenhar uma política mais universal e inclusiva".

"O processo de inclusão é complexo, não adianta implantar rampa, ensinar libras... , se não mudar as atitudes das pessoas, são as atitudes das pessoas que incluem".

"Qualquer forma de conhecimento agrega, esse curso, além de agregar muito profissionalmente, acrescenta ainda mais no lado pessoal e humano do funcionário, à vida profissional e pessoal pelos mesmos motivos: abre uma nova possibilidade de comunicação e compreensão sobre as pessoas com deficiência, seja auditiva ou outra qualquer".

"Atendimento de excelência? Para mim é muito mais do que isso, trata-se de uma atitude de humanidade, respeito ao próximo, lógico que com isso melhoramos nosso atendimento, é um público que vinha sendo deixado à margem não só pelo Sistema Financeiro, com certeza cria um diferencial temporário, já que outras instituições podem adotar estratégia semelhante; e pode ser considerado um índice de excelência no atendimento, talvez até se torne um "commoditie" em atendimento".

"Eu acredito que não haja nenhuma ação do banco que não vise captação..., mas tenho certeza também que ele tem compromisso com o social, qualquer cliente satisfeito, bem atendido é um potencial consumidor dos produtos e serviços do banco ou de qualquer 
empresa, todo mundo gosta de ser bem atendido, valorizado. Vai contribuir para o crescimento da carteira de clientes, mas não sei se o aumento será significativo".

Percebemos, pelas respostas dos entrevistados, que há um compromisso grande do banco em promover à acessibilidade e inclusão do deficiente auditivo em seu atendimento bancário, entretanto, a maioria considera que para haver efetividade nesses projetos, é necessário qualificação em Libras, mas principalmente mudar a atitude das pessoas, porque são as atitudes que incluem, somente ser atendido em Libras não vai garantir bom atendimento nem fidelização, que as pessoas precisam compreender a importância da ética nas relações, tem que haver sinceridade, coerência, honestidade e transparência, entender que com o surdo é "olho no olho" que funciona, se perceber insegurança nas informações, o deficiente vai difamar a empresa para toda sua comunidade e aí o risco de imagem é maior, a empresa fica mais exposta. 


\section{CONSIDERAÇÕES FINAIS E RECOMENDAÇÕES}

Segundo dados do IBGE (2000), no Brasil existem mais de 24,6 milhões de pessoas com deficiências, baseados nisso, podemos nos conscientizar das barreiras que existem à nossa volta, barreiras estas quase imperceptíveis, mas que se modificadas, representaria um diferencial enorme na vida destas pessoas, proporcionando qualidade de vida e bem estar.

O fato de existirem tantos deficientes contribuiu para que o poder público constatasse a necessidade de se ter legislações específicas, que respeitem, valorizem e potencializem essas pessoas, incluindo-as assim, às condições sociais que todos os cidadãos merecem e devem receber do Estado.

A inclusão faz parte do compromisso ético de promover a diversidade, respeitar a diferença e reduzir as desigualdades sociais. O Instituto Ethos (2002) afirma que esta realidade coloca a inclusão de pessoas com deficiência entre os temas mais importantes a serem tratados pela sociedade.

Segundo Sassaki (2002):

\footnotetext{
"As empresas inclusivas caracterizam-se por demonstrarem transformações pequenas e grandes, nos ambientes físicos (espaços externos e internos, equipamentos, aparelhos e utensílios, mobiliários e meios de transporte), nos procedimentos técnicos, nas formas de comunicação (visual, auditiva, por sinais, por computador) e principalmente na mentalidade de todas as pessoas, inclusive da própria pessoa com deficiência". (p. 45).
}

Salienta-se que as práticas inclusivas adotadas pelas empresas são justificadas e reforçadas por uma série de benefícios por elas trazidos. Entretanto, este retorno depende do quanto de empenho e investimento na implantação da política de inclusão social no ambiente de trabalho a empresa faça.

Segundo publicação do Instituto Ethos "O que as empresas podem fazer pela inclusão social de pessoas com deficiência" (2002), existem uma série de vantagens cumulativas para as empresas inclusivas, entre elas, os ganhos de imagem tendem a fixar-se a longo prazo.

O termo acessibilidade começou a ser utilizado com muita freqüência nos últimos anos, em assuntos de reabilitação, saúde, educação, transporte e ambientes de empresas de atendimento ao público em geral. 
De acordo com o artigo $8^{\circ}$ do Decreto 5.296 de 02/12/2004, considera-se acessibilidade:

\footnotetext{
"condição para utilização, com segurança e autonomia, total ou assistida, dos espaços, mobiliários e equipamentos urbanos, das edificações, dos serviços de transporte e dos dispositivos, sistemas e meios de comunicação e informação, por pessoa portadora de deficiência ou com mobilidade reduzida".
}

Vivemos em uma sociedade capitalista, somos induzidos a acreditar que qualquer ação adotada por uma empresa seja voltado ao lucro.

Um dos motivos de incentivo à realização dessa pesquisa foi exatamente verificar se o projeto adotado pelo Banco do Brasil de qualificar funcionários do atendimento nas agências em LIBRAS para atendimento aos deficientes auditivos representa apenas uma preocupação com a responsabilidade social, promovendo a inclusão do surdo às agências ou se a empresa estaria visando captação de negócios e novos clientes, ou ambos.

Com base nos dados obtidos, percebemos que as ações em promoção da acessibilidade e inclusão de deficientes auditivos ao Banco do Brasil abrange as duas questões: a responsabilidade social como estratégia de oferecer um diferencial competitivo e, ao mesmo tempo, conquistar novos nichos de mercado, pois trata-se de uma instituição comercial, que visa lucro, não haverá inclusão se não houver ganho de negócios, mas acredita-se que o compromisso com a responsabilidade social seja maior, afinal, esta preocupação já existia antes mesmo da obrigatoriedade da lei.

Espera-se que no futuro, esse compromisso se propague para outras instituições, que o valor das pessoas surdas seja realmente reconhecido, e que a oferta do presente seja efetivada de forma global, que não seja só "da boca para fora", pois eles já sofreram muito sendo excluídos da sociedade.

A inclusão é um tema polêmico e criticável, os entrevistados, todos eles funcionários da instituição, demonstraram muita credibilidade no compromisso do banco, acreditam que mesmo em si tratando de uma instituição comercial, que visa ao lucro, não seja apenas captação de negócios, mas que realmente esteja promovendo a inclusão dos surdos, afinal, ao ser incluído no mercado de trabalho, eles passam a fazer parte dos bancos, proporcionar um atendimento diferenciado aos mesmos contribuirá para melhorar sua qualidade de vida.

Com base nas respostas dos entrevistados, foi possível a conclusão de que as ações adotadas pelo banco correspondem a postura de responsabilidade social e de busca pela excelência no atendimento. São sinais de inclusão e acessibilidade de clientes com deficiência auditiva ao banco, na linguagem da responsabilidade social. 
Com base nas respostas assinaladas por dez pessoas com deficiência auditiva, todas elas inseridas no mercado de trabalho e clientes do banco, verificamos que eles conseguem realizar transações bancárias sozinhos, inclusive no atendimento nas agências, a maioria assinalou que ainda encontra dificuldades de comunicação, mas já perceberam que o banco está treinando funcionários em Libras com o objetivo de oferecer a eles um atendimento diferenciado, consideram que essa preocupação vai acrescentar credibilidade ao banco, vai melhorar sua qualidade de vida e eles falarão sobre isso à sua comunidade.

Isso nos leva a crer que eles trarão essa comunidade ao banco, e conseqüentemente, trará novos clientes e captação de negócios, embora acreditemos que isto não seja o objetivo do banco promovendo a inclusão desses deficientes, há que se considerar que como se trata de uma instituição comercial, que visa ao lucro, será uma via de mão dupla. 


\section{REFERÊNCIAS}

ACEVEDO, Cláudia Rosa; NOHARA, Jordan. Monografia no curso de Administração. 3. Ed. São Paulo: Editora Atlas, 2009.

APADA - Associação de Pais e Amigos dos Deficientes auditivos do Distrito Federal. Disponível em: <http://www.apadadf.org.br/>. Acesso em 19 jun. 2010.

AUTOR desconhecido. Poema do Surdo. Disponível em <http://escolasinclusivas.blogspot.com/2010_09_01_archive.html>. Acesso em 20 set. 2010.

BAHIA, Melissa Santos. Responsabilidade Social e diversidade nas organizações: Contratando pessoas com deficiência. Rio de Janeiro: Editora Qualitymark, 2006.

BANCO DO BRASIL, Agência de Notícias do Banco do Brasil. Brasília/DF, 2010.

BANCO DO BRASIL - Sustentabilidade. Disponível em:

http://www.bb.com.br/portalbb/home1,8305,8305,0,0,1,6.bb. Acesso em 03 dez. 2010.

BRASIL. Decreto Lei 3.298/1999 de 20 de dezembro de 1999. Brasília: Gabinete da Presidência da República, 1999. Disponível em:

<http://www.planalto.gov.br/ccivil/decreto/d3298.htm>. Acesso em 21 jun. 2010.

BRASIL. Lei 10.098/2000 de 19 de dezembro de 2000. Brasília: Gabinete da Presidência da República, 2000.

CREDÍDIO, Fernando. Ecorrelações: a prática da sustentabilidade. Revista Filantropia e Gestão Social, São Paulo, n. 44, 2010.

DIREITOS DAS PESSOAS PORTADORAS DE DEFICIÊNCIA - "CARTILHA DA

INCLUSÃO" , disponível em

<http://www.integrando.org.br/IMG/doc-193.pdf>. Acesso em 20 ago. 2010).

FEBRABAN - Federação Brasileira dos Bancos. População com deficiência no Brasil: fatos e percepções. São Paulo: Febraban, 2006.(Coleção Febraban de inclusão social). Disponível em <www.febraban.org.br>. Acesso em 12 ago. 2010.

FEBRABAN - Federação Brasileira dos Bancos. Manual de acessibilidade para agências bancárias. São Paulo: Febraban, 2006. (Coleção Febraban de inclusão social). Disponível em <www.febraban.org.br>. Acesso em 12 ago. 2010.

FEBRABAN - Federação Brasileira dos Bancos. Atendendo bem pessoas com deficiência. São Paulo: Febraban, 2006. (Coleção Febraban de inclusão social). Disponível em <www.febraban.org.br>. Acesso em 12 ago. 2010. 
FEBRABAN - Federação Brasileira dos Bancos. Pessoas com Deficiência: Direitos e Deveres. São Paulo: Febraban, 2006. (Coleção Febraban de inclusão social). Disponível em <www.febraban.org.br>. Acesso em 12 ago. 2010.

FENEIS - Federação Nacional de Educação e Integração dos Surdos. 2006. Disponível em: 〈http://www.feneis.org.br>. Acesso em: 20 jun.2010.

FUNDAÇÃO DO BANCO DO BRASIL. 2006. Disponível em:

<http://www.fbb.org.br>. Acesso em: 20 jun. 2010.

IANNARELLI, Thaís. Normalização da Responsabilidade Social. Revista Filantropia e Gestão Social, São Paulo, n. 45, 2010.

Instituto Ethos de Empresas e Responsabilidade Social - ETHOS. O que as empresas podem fazer pela inclusão das pessoas com deficiência. São Paulo: Instituto Ethos, 2002.

MATIAS, Damião Tiburtino. Sustentabilidade nos negócios financeiros (2009, p. 45). Mestrado (Ciências Sociais) - Pontífica Universidade Católica de São Paulo - PUC/SP, São Paulo, 2009.

MATIAS-PEREIRA, José. Metodologia Científica: Manual de Pesquisa Científica.

Universidade de Brasília: Brasília, 2006.

NOVAES, Edmarcius Carvalho. Surdos: educação, direito e cidadania. Rio de Janeiro: Editora Wak, 2006.

SÁ, Nídia Regina Limeira de. Cultura, poder e educação de surdos. São Paulo: Editora Paulinas, 2006.

SURDO. Site de apoio aos deficiente auditivos e familiares. Disponível em: <http://www.surdo.org.br >. Acesso em: 19 jun.2010.

UNIVERSIDADE CORPORATIVA BANCO DO BRASIL. Disponível em:

$<$ https://www13.bb.com.br/appbb/portal/bb/unv/func/fer/index.jsp. $>$. Acesso em: 20 jun.2010. 


\section{ANEXOS}

\section{Anexo A - Primeira Entrevista Realizada}

\section{1 - Há quanto tempo trabalha no Banco?}

20 anos

\section{2 - Que cargo ocupa?}

Atualmente, Assessor Pleno (DIPES - Diretoria de Pessoas)

3 - Que grau de envolvimento tem com o compromisso do Banco com a responsabilidade social, especificamente a disponibilização do Curso de Libras (Linguagem Brasileira de Sinais) a seus funcionários?

$\mathrm{Na}$ verdade, é difícil este comprometimento, porque o curso de libras agora está nos pólos, cada Diretoria, uma parte da empresa trabalha com pólos, são 20 polos de regionais, cada regional tem responsabilidade de mobilizar a sua jurisdicionante a convencer os gestores das agências envolvidas para que os funcionários sejam treinados, temos esta ação por iniciativa própria nossa, e temos a ação que é da FEBRABAN (Federação Brasileira dos Bancos) que vai disponibilizar no site um curso para todos os bancos, um curso de 15 horas. Agora, pela experiência que temos nos pólos, sabemos que é preciso contato pessoal, é fundamental que os primeiros contatos sejam presenciais, somos convencidos da importância para compreender a semântica da língua, portanto, no âmbito direto, somos motivadores para este curso dentro desta empresa.

4 - Seria mais um compromisso na busca de excelência no atendimento, visando manterse na liderança do sistema bancário nacional?

Esta sua pergunta é complicada, em primeiro lugar, acho que se as pessoas que fizerem o curso de libras entenderem que é uma maneira de rever, de revisitar o comprometimento das pessoas com as pessoas, eu acho que não existe atendimento de excelência, todo atendimento vai ter falhas, e vai ter riscos, a partir do momento que eu te recebo, posso não estar em um dia de mau humor e posso não contemplar este bom atendimento, você também pode não estar num dia de bom humor e posso não conseguir te atender bem, não porque eu não tenha 
uma boa educação, não seja muito eficaz, mas porque você não está bem. Para mim, o bom atendimento é melhor que o atendimento de excelência, porque o bom atendimento é quando você consegue satisfazer ou encontrar aquela dúvida que o cliente busca, e propor soluções que nem ele mesmo esperava, isto nem sempre é o que o banco põe na meta, nem sempre a meta que temos de vender um produto, seja o que aquele cliente precisa, e ter conhecimento dos produtos da empresa em que você trabalha é essencial, o que vai vender e a quem vai atender, não é a libra que vai resolver, quem tiver este contato pense em duas coisas, primeiro tem que olhar o surdo no olho, criar o hábito de fazer isto, quando começa a estudar libras, entende que com o surdo, é olho no olho que funciona, é preciso olhar diretamente para quem está falando, ser transparente porque o surdo pega no ar uma tentativa de falsidade, de mentira, como ele só tem contato visual. Quando as pessoas que estão fazendo este curso conseguir entender esta idéia, com certeza vão mudar seu padrão de atendimento, mas isto não coloca o banco como frente de mercado, ele está na frente de mercado por outros motivos, nosso atendimento, venhamos e convenhamos, não é dos melhoras, e nem está longe de ser melhor, por fatores da demanda, poucos funcionários, nosso processo tecnológico é lento, nossa plataforma tecnológica é muito mais lenta, muito mais confusa, se juntar todos esses elementos, é difícil atender bem com tantas pressões e tantas metas absurdas, claro que a libra te dá mais uma alternativa de competitividade, mas não é tudo. Sua pergunta é complicada.

\section{5 - Com o treinamento de funcionários, muitos acreditam realmente em inclusão social, porém, há quem diga que esteja visando captação de negócios e novos clientes. Qual sua opinião?}

Duas coisas, sua pergunta é muito legal, eu acho que está certo, tem as duas visões, quando eu me envolvi com a deficiência, e não só com a libra, a libra é um dos processos de inclusão, é um elemento, existem várias deficiências, existe o braile, existe o deficiente surdo, cego, cadeirante, tanta coisa , são muitas informações, então o processo de inclusão é complexo, não adianta implantar rampa, ensinar libras, adaptar computador, se você não mudar a atitude das pessoas, são as atitudes das pessoas que incluem, somos incluídos porque somos pessoas, temos diferentes formas de lidar, acredito que de alguma forma nossa atitude é um passo até grande, quem está se envolvendo, acaba começando a gostar, descobrindo que pode, que não é tão diferente, o outro é diferente, mas é possível entender, mas como estamos numa empresa comercial, que visa lucro, e prá mim, é o coração do sistema capitalista, o banco pulsa capitalismo, tem capitalismo nos poros, se a gente não consegue entender a idéia de que há ganho de negócios, e novos nichos de mercado, não consegue vender a inclusão, então a gente 
aproveita a lei, aproveita o momento, verbaliza novos clientes, tem implemento nos negócios, motiva a inclusão, isto se torna o diferencial da empresa, quando outra empresa percebe que você faz estas coisas, o nível de relacionamento aumenta, há maior envolvimento, começa a ter um padrão de relacionamento melhor, pode chegar a isso, eu ainda acho que é um sonho, estamos começando, vai fazer 3 anos já que a lei saiu, 3 anos de obrigatoriedade, 7 anos da lei que formaliza a inclusão saiu, mas a obrigatoriedade, foi nos últimos 3 anos. Prá ver o tamanho da resistência, a empresa não quer incluir ninguém, somente quem tem dinheiro, com a lei de responsabilidade, o mundo está mudando, você tem que ter negócios o tempo todo, se quebrar você quebra junto, estas são as mudanças que temos que implementar, até para incluir, hoje não temos deficientes nos grandes cargos, mas chegará o momento que elas chegarão, e aí, se não respeitarmos eles agora, quando chegarem lá, que respeito vão ter com a gente? Então, inclusão é sempre mão dupla, a gente não faz só porque gosta, existe a ética, é claro que é um negócio que envolve todo mundo. Faz parte.

6 - Acredita que o deficiente auditivo, ao ser atendido por funcionário que fale sua linguagem, que diga que foi treinado para melhor atendê-lo, se sinta valorizado, "importante" para o Banco? E que isto lhe traga melhorias em qualidade de vida?

Como tudo precisa de dinheiro, os bancos conseguiram, no Brasil principalmente, não sei se no resto do mundo, os bancos conseguiram tudo passar por eles hoje, todo os negócios passam pelo banco, acaba que o surdo é incluído no banco, mas os surdos vivem sem banco, vivem completamente sem eles, não precisavam antes, não precisam agora, mas os bancos precisam deles, as empresas possuem surdos hoje, e outras deficiências também, agora quando ele é atendido, só ser atendido por pessoa que fala seu idioma, não garante nem bom atendimento nem fidelização, e se as pessoas não compreenderem que a ética na relação com a deficiência, é mais forte do que o esperado, tem que ser mais sincera, quando dependo de alguém que consegue ler o que eu não consigo, não é só dominar o idioma, é preciso coerência, honestidade e transparência, se ele desconfiar, se você criar aspecto de insegurança, ou mesmo mentir, que é o que acontece muitas vezes, você vende um produto que é uma mentira, e aí o cliente volta para reclamar, você diz que explicou sobre o produto, ele diz que não, que você falou que o produto era bom, ele vai difamar tudo para toda sua comunidade e aí o risco de imagem é muito maior, a comunidade surda é muito unida, fez para um surdo, fez para todos, é um risco, a gente fica muito mais exposto.

7 - E que este cliente, satisfeito com o Banco, contribua para o crescimento da carteira de clientes e captação de negócios? 
Com certeza, o dia que o banco realmente capacitar, temos um exemplo no Rio de Janeiro, fomos procurar identificar agências que atendiam surdos, nos direcionamos a uma e perguntamos, vocês atendem surdos? Eles disseram que não, vocês atendem sim, não é possível, vocês têm contas da FENEIS (Federação Nacional de Educação e Integração dos Surdos) e não sabem. Fomos ao atendimento da Agência, os funcionários disseram atendemos sim, aí descobrimos que tinham 900 contas correntes de surdos. Imagina se cada cliente surdo depositar 100 reais por mês, quantas propostas de negócios podem ganhar. O Gestor então entrou em contato com a FENEIS que fechou sua folha de pagamento na Agência, e se tornou um cliente diferenciado, a gente filmou o atendimento, foi muito legal. Naquela época tinham 900 contas, hoje deve ter muito mais. Uma agência de médio porte, que não conhecia seus clientes, um absurdo, mas uma verdade, se você tem um negócio, tem obrigação de conhecer seus produtos. Quando o surdo é bem atendido, ele fica lá, vai se reunir mais vezes onde é bem tratado, e leva a comunidade dele. Em Florianópolis, temos dois centros, os 2 atendem surdos, mas os clientes se identificam mais com um, e é só lá que procuram, alguma coisa acontece, a gente não sabe o que é, ele se identifica mais naquela Agência, fica satisfeito e aí leva a comunidade inteira, é bem interessante, quando isto estiver propagado no Brasil, vamos ter agências pólo, com atendimento diferenciado, mas só quando convencermos a empresa, vão ser criadas agências modelo para surdos.

\section{8 - Já fez Curso de Libras?}

Tentei duas vezes, não consegui terminar por força de circunstâncias, até porque eu falo pouco.

\section{9 - Tem algo a acrescentar sobre o assunto?}

Não, nada a acrescentar, só espero que os funcionários gostem do curso, ele acaba desinibindo a gente. 


\section{Anexo B - Questionário Aplicado aos Deficientes Auditivos}

1) Sexo:

2) Idade:
( ) masculino
( ) feminino

( ) anos

3) Há quanto tempo é cliente do banco?
( ) meses
( ) anos

4) Quais os benefícios que sua conta bancária te proporciona?

( ) recebimento de salário

( ) empréstimos

( ) aplicações

( ) cheques

( ) outros

5) Utiliza celular para alguma transação bancária?

( ) sim, recebe mensagens de transações por SMS

( ) não

6) Realiza transações bancárias pela internet?

( ) $\operatorname{sim}$

( ) não

7) Utiliza o Terminal de Auto Atendimento - TAA?

( ) sim, sozinho

( ) sim, por segurança, vai acompanhado

( ) não

8) Quando necessita de atendimento na agência, você:

( ) vai sozinho

( ) vai acompanhado por um ouvinte

( ) por ter dificuldade no atendimento, tem procurador que faz isso por você

9) Quando vai à agência, de que forma se comunica com o funcionário:

( ) faz perguntas escritas em português

( ) em Linguagem Brasileira de Sinais - LIBRAS

( ) por gestos e leitura labial

10) Alguém já te falou que o banco está qualificando funcionários em Libras para melhor atendê-lo?

( ) $\operatorname{sim}$ 
( ) não tem conhecimento disso

11) Sabendo que o funcionário está aprendendo Libras para melhor atendê-lo te traz satisfações pessoais?
( ) $\operatorname{sim}$
( ) não
( ) indiferente

12) Acredita que o banco esteja promovendo acessibilidade e inclusão do surdo:

( ) para oferecer um atendimento de excelência

( ) visando novos clientes e lucro

13) Qual melhor forma de atendimento bancário em sua opinião:
( ) agência, sozinho, atendido em Libras
( ) agência, acompanhado de um ouvinte
( ) TAA, sozinho
( ) TAA, acompanhado
( ) internet

14) Sabendo da preocupação de seu banco em oferecer atendimento ao surdo em Linguagem Brasileira de Sinais faz você recomendá-lo a outros deficientes auditivos?
( ) $\operatorname{sim}$
( ) não
( ) indiferente

15) Está satisfeito com o atendimento de seu banco?
( ) $\operatorname{sim}$
( ) não
( ) acredita que melhorará muito quando os funcionários dominarem a Libras 
Anexo C - Alfabeto Manual do Deficiente Auditivo

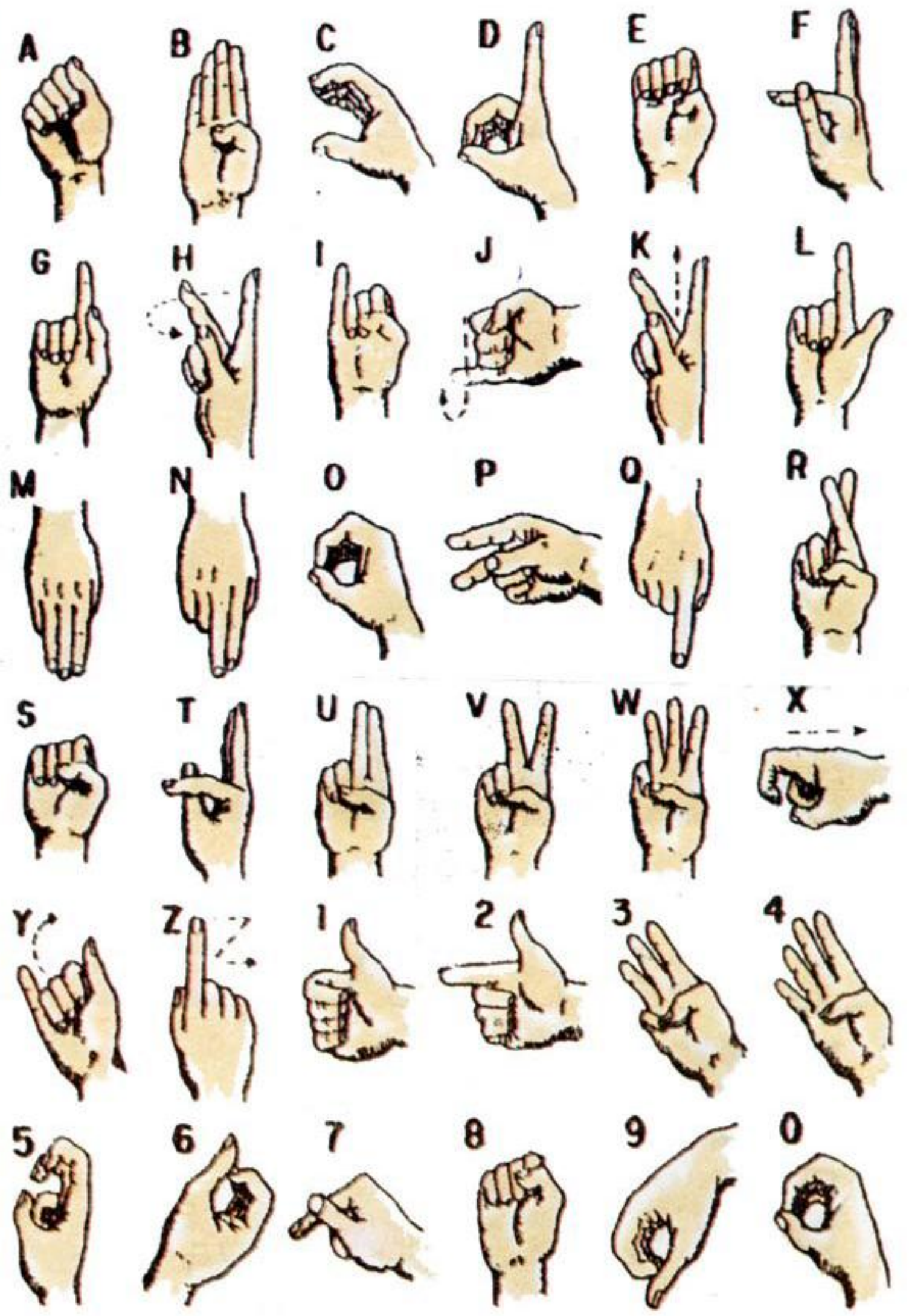

